\title{
Raposas Matreiras, Bonecas Cientistas e Cavaleiros que Adoecem por Apanhar Sol: A Química na Literatura para Jovens
}

\author{
Sérgio P. J. Rodrigues \\ Centro de Química de Coimbra e Departamento de Química, Universidade de Coimbra \\ spjrodrigues@ci.uc.pt
}

\begin{abstract}
A presença da Química na Literatura encontra-se muito para além das referências directas a esta Ciência que aparecem em obras literárias através de compostos e processos químicos, ou de personagens que se dedicam à Química ou a evocam. A ubiquidade da Química manifesta-se também, muitas vezes de forma subtil e quase invisível na vida das personagens e no meio que as rodeia. Revela-se nas memórias do passado que a Química contribuiu para mudar, na Tecnologia e modos de vidas actuais e nos processos, aparentemente vulgares, que a Química ajudou a explicar. O presente artigo procura ilustrar alguns aspectos da presença da Química na Literatura, em particular na literatura juvenil de autores de língua portuguesa, realçando alguns aspectos que poderão ser interessantes para o ensino da Química a jovens.
\end{abstract}

\section{INTRODUÇÃO}

O que é que liga uma raposa matreira, uma boneca atrevida, alguns jovens que se aventuram em terras da fantasia e um cavaleiro que adoeceu e foi socorrido por frades, depois de uma viagem de volta à Dinamarca? Serem personagens de livros maravilhosos, mas também poderem abrir portas para o mundo da Química aos jovens e adultos que os possam ler com outros olhos.

A Química tem, desde o seu aparecimento como Ciência, entusiasmado e surpreendido gerações de jovens. No presente texto procurarei realçar a relação proveitosa que sempre existiu entre a Química e a Literatura, em particular na literatura acessível aos jovens. Michael Faraday, por exemplo, que ficou fascinado pelos livros que leu enquanto aprendiz de encadernador, em especial com "Conversations on Chemistry”, publicado pela primeira vez em 1805 pela divulgadora de Ciência Jane Marcet [1], acabou por se tornar um dos maiores cientistas de todos os tempos. Mais tarde, a transcrição das lições de Michael Faraday, realizadas para jovens nos Natais de 1848 e 1860, “A História Química de uma Vela” [2], inspirou milhares de futuros cientistas, muitos deles químicos. Mas não têm sido só os livros de divulgação de Ciência que têm entusiasmado os jovens: numerosos livros em que a Ciência aparece de forma mais subtil têm também inspirado muitos jovens. Por exemplo, o cientista israelita Dan Shechtman, que recebeu o prémio Nobel da Química em 2011 pela descoberta dos quasi-cristais, declarou em entrevistas que a leitura (pelo menos 25 vezes), enquanto criança, do livro de Jules Verne, de 1874, “A Ilha Misteriosa”, foi fundamental para a sua escolha da carreira científica. Este livro, em particular, assim como "Vinte Mil Léguas Submarinas", publicado em 1870, apresentam pormenores químicos muito precisos, alguns de natureza visionária, que têm sido analisados por diversos autores (veja-se, e.g., a referência 3).

Obras como o "Dom Quixote” de Miguel de Cervantes ou o "Moby Dick" de Herman Melville não eram inicialmente destinados a jovens. No entanto, ao longo da história da humanidade, os jovens (que o podiam fazer) sempre se apropriaram dos romances de aventuras [4], e, através destes, tomaram contacto com aspectos da Ciência, Tecnologia e Cultura do seu tempo ou do passado. Nem sempre esses aspectos, em particular aqueles que estão relacionados com a Química, são evidentes, mas, posso afirmar que em todas as obras literárias que conheço, incluindo as de literatura para jovens, existem relações com a Química [5].

O número de bons livros e leituras populares para jovens é imenso. Assim, neste artigo irei concentrar-me essencialmente em alguns exemplos, ainda não explorados na sua relação com a Química, de obras de autores de língua portuguesa.

Aspectos muito interessantes, mas que estão para além do objectivo deste artigo, acerca da Química complexa e mágica dos livros da série "Harry Potter" de J. K. Rawling podem ser encontrados, por exemplo, na referência 6 . Também o relativamente recente interesse dos jovens pela literatura fantástica envolvendo vampiros e outros seres sobrenaturais escapa ao âmbito deste artigo (veja-se, no entanto, a referência 5).

\section{AS DESCOBERTAS QUÍMICAS DA RAPOSA}

Aquilino Ribeiro é um escritor que teve uma notável intervenção cívica e política, tendo, no início do século Xx, passado pela acção revolucionária, a qual segundo se sabe, e, de acordo com as suas memórias, originou uma explosão em 1907 que vitimou dois dos seus companheiros de conspiração. Estava, por isso, com certeza, familiarizado com a Química e a Tecnologia do seu tempo, o que é, de resto, claramente reconhecível, por exemplo, no romance que publicou em 1944, "Volfrâmio”. Mas isso não é relevante para a química que podemos encontrar em "O Romance da Raposa” [7], datado de 1929 e dedicado ao seu filho Aníbal. 
Aquilino Ribeiro inspira-se em narrativas anteriores, de origem culta e popular, para criar um livro que nos revela com pormenor os mecanismos da astúcia e da inteligência, mas também aspectos da descoberta científica e da química que nos rodeia. Em particular, o odor característico dos animais (Figura 1) e os disfarces que a raposa usa para enganar o lobo, primeiro empregando mel para colar palha e depois usando resina para colar folhas de couve, são temas químicos a explorar com proveito. Porque cheiram os animais de forma diferente uns dos outros? Porque é que o mel se dissolve em água e a resina dos pinheiros não?
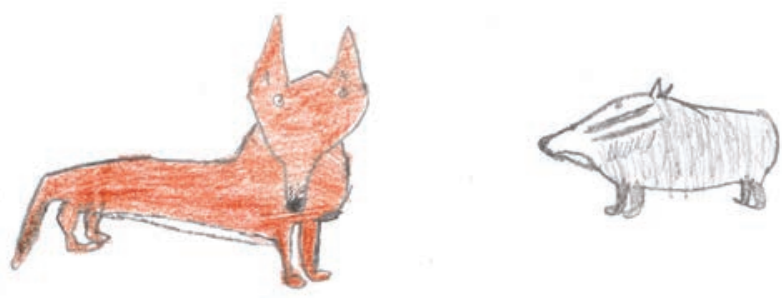

Figura 1 - A raposa e o texugo, personagens de "O Romance da Raposa" de Aquilino Ribeiro, a trocarem informação química através dos seus odores. Desenho original do filho do autor, Miguel de 9 anos

Podemos começar com a forma como a raposa faz a sua descoberta científica da utilização do mel para se disfarçar. Foi por acaso que isso aconteceu (dir-se-ia hoje, por serendipidade), ao ficar toda lambuzada de mel, depois de atacar uma colmeia. O mel, que a tudo se colava, sugeriu-lhe uma ideia para se disfarçar. Teve depois de validar os seus ensaios, replicar e optimizar os resultados. No final tinha um resultado que pôde testar: um disfarce que o lobo não reconheceu. Entretanto, tendo a raposa revelado o seu segredo, o lobo passou a testar os animais, molhando-os com água. Assim, a raposa teve de aperfeiçoar o seu disfarce: inventar um que fosse impermeável. Nesse momento já sabia o que queria e foi provavelmente mais fácil fazer os seus ensaios. Mas, mesmo assim, teve que experimentar e testar várias hipóteses e, no final, encontrou o material adequado para o disfarce: a resina de pinheiro.

Explicar as diferenças de solubilidade destes dois materiais (mel e resina de pinheiro), em termos qualitativos, não é muito difícil e pode ser adequado a qualquer idade e nível de conhecimentos. O mel é solúvel em água (embora a dissolução possa demorar algum tempo) porque é uma mistura essencialmente de açúcares. E os açúcares têm partes (dizemos em Química: grupos funcionais) que se ligam bem à água. Para os alunos mais avançados pode falar-se de ligações de hidrogénio e dos tipos de açúcares presentes no mel: essencialmente D-(+)-glucose (Figura 2, 1) e D-(-)-frutose (Figura 2, 2) que estão presentes em igual quantidade (cerca de 65-75\% em massa) e que se designam por açúcares invertidos. Mas o mel tem também quase 20\% de água, além de outros açúcares, incluindo sacarose (Figura 2, 3) [8].

Por outro lado, a resina é uma secreção dos pinheiros que consiste numa mistura de compostos que são insolúveis em água porque têm estruturas e formas moleculares que não estabilizam a sua solvatação pelas moléculas de água. A composição das resinas de pinheiro depende muito da espécie, mas contém essencialmente terpenos voláteis (cerca de 30\%), como o $\alpha$-pineno (Figura 3, 4) que separados dão a terebentina, ou aguarrás, e ácidos resínicos sólidos muito pouco voláteis (cerca de 60-70\%) como os ácidos pimárico e ácido abiético e os seus derivados que originam a colofónia, ou pez louro, que tem bastante interesse comercial e químico. Estes ácidos partilham a mesma fórmula química $\mathrm{C}_{20} \mathrm{H}_{30} \mathrm{O}_{2}$, mas têm propriedades diversas. No caso dos pinheiros típicos de Portugal predominam os ácidos palústrico e levopimárico (Figura 3, 5 e 6) enquanto noutras espécies de pinheiros predominam outros ácidos [9].<smiles>OCC1O[C@H](O)[C@@H](O)[C@H](O)[C@H]1O</smiles><smiles>OC[C@H]1O[C@](O)(CO)[C@@H](O)[C@@H]1O</smiles><smiles>OCC1O[C@@H](OC2(CO)O[C@H](CO)C(O)[C@H]2O)[C@H](O)C(O)[C@@H]1O</smiles>

Figura 2 - Açúcares mais abundantes no mel: D-(+)-glucose (1); D-(-)-frutose (2); sacarose (3)

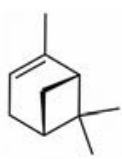

4

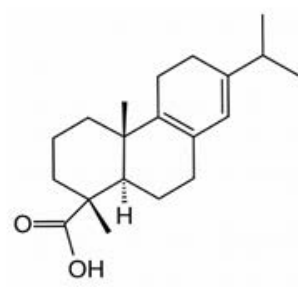

5

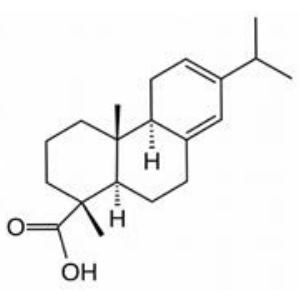

6

Figura 3 - Compostos mais abundantes da resina dos pinheiros-bravos (Pinus pinaster) [9] comuns em Portugal: (+)- $\alpha$-pineno (4); ácido palústrico (5); ácido levopimárico (6) 
Um outro aspecto químico que podemos relacionar com o "Romance da Raposa” é, como foi referido anteriormente, o odor dos animais. A descoberta da explicação química dos odores dos animais e da composição do suor, demorou até ao aparecimento dos métodos modernos da espectrometria de massa, cromatografias gasosa e líquida de alta resolução. E, ainda, das espectroscopias vibracional e de ressonância magnética, química computacional e métodos de determinação das estruturas moleculares por difracção de raios $\mathrm{X}$.

Em “A Montanha Mágica”, datado de 1924, do escritor Thomas Mann, Hans Castorp e o médico a quem este faz perguntas sobre Ciência, o Dr. Behrens, ainda não têm os meios necessários para saberem o que hoje nos parece fácil de obter: faz-se um espectro dos odores e surgem centenas de compostos, muitos deles já identificados e outros desconhecidos que é necessário ainda identificar. No final, os odores aparecem-nos como perfumes característicos de cada espécie, únicos para cada indivíduo, que são muito mais complexos do que aqueles que poderíamos obter pela simples mistura de alguns dos compostos mais abundantes ou mais odoríficos.

Um cão treinado pode identificar compostos voláteis característicos de explosivos, drogas ou mesmo de doenças. E pode notar alterações de comportamento, por exemplo, o medo, o qual pode ser também associado a processos químicos, como veremos mais adiante. Estes animais estão envoltos numa nuvem complexa de informações químicas que lhes chegam ao nariz, ou que eles aspiram, aumentando assim o fluxo de moléculas analisadas.

Para o texugo, e também para nós, humanos, a raposa cheira mal (o que esta concorda, afirmando no livro, que o texugo é um animal muito mais asseado do que ela). No entanto, parece ser hoje senso comum que os texugos cheiram mal, em especial uma variedade que se tornou famosa em desenhos animados e filmes. Em que é que ficamos? Quem cheira pior?

A raposa tem razão, mas os desenhos animados também. Os texugos vulgares têm um sentido do olfacto muito apurado e são muito organizados e higiénicos no uso das latrinas. Têm, no entanto, uma glândula anal que pode libertar uma enorme quantidade de compostos [10], os quais têm um cheiro almiscarado, que de resto para a maioria das pessoas não é assim tão desagradável e Aquilino sabe isso. Destes compostos, realça-se o nonanal (Figura 4, 7) que nós humanos também libertamos e que tem a particularida- de de atrair mosquitos! Também o nosso suor, em especial o dos pés, pode conter compostos bastante mal-cheirosos como o ácido butanóico (Figura 4, 8), que está também presente no queijo, vomitado e frutos fermentados de algumas árvores. Entretanto, o texugo fedorento do continente americano liberta compostos que contêm enxofre [11] como o isoamiltiol (Figura 4, 9) e pode produzir cheiros nauseabundos se se sente em perigo.

Finalmente, as raposas são, de facto, muito menos asseadas que os texugos vulgares e por onde passam deixam cheiros desagradáveis. Das suas fezes, por exemplo, obteve-se o composto 2,4,5-trimetil-3-tiazolina (Figura 4, 10) que tem sido usado como repelente, havendo algumas dúvidas se este funciona como um indutor de medo ou se é simplesmente repugnante [12].

Não ter odor é na verdade impossível, pois significaria não suar (o que faz parte dos mecanismos de arrefecimento dos seres humanos) nem emitir compostos voláteis. O assassino de "O Perfume" de Patrick Süskind padece desse fantástico problema, o que é um aspecto químico interessante mas fora do âmbito deste artigo [5].

\section{ReFleXos dA APRENDIZAGEM DA QUÍMICA NA LITERATURA}

Em “O Papá das Pernas Altas”, de 1912, da escritora inglesa Jean Webster [13], a jovem heroína escreve cartas descrevendo o que está a aprender no colégio. Numa destas dá-nos a sua primeira impressão sobre a Química: Comecei a estudar Química, assunto muito invulgar. Nunca vi nada semelhante. Moléculas e átomos são os materiais empregados, mas só daqui a um mês estarei em condições de discuti-los com mais consciência.

Mais à frente, já dominando alguns conhecimentos desta ciência, Jerusha diz: Tenho de ir para o laboratório tratar de uma questão de ácidos, sais e bases. Fiz um buraco do tamanho de um prato no meu avental de química com ácido clorídrico. Se a teoria funcionasse, deveria poder neutralizar aquele buraco com amónia bem forte, não devia? Esta hipótese que se nos afigura cómica ilustra uma questão importante: a ligação entre a teoria e a prática da Química não é intuitiva e apresenta bastantes dificuldades para os estudantes. A propósito deste texto, os químicos Catty Cobb e Monty Fetterolf [14] chamam a atenção para que, no início do século Xx, a piada da situação deveria ser óbvia para o leitor típico, além de que seria normal que os jovens trabalhassem com ácidos e bases fortes logo que contactavam com a Química! Actualmente, talvez o ensi-

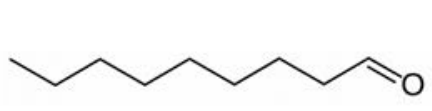

7

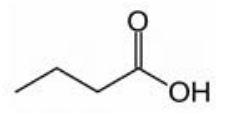

8
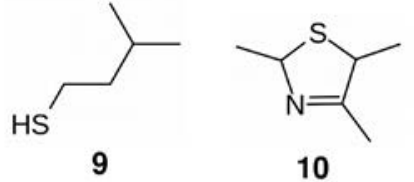
no da Química se tenha tornado mais verboso, abstracto e afastado da prática. E, no entanto, como bem sabem os químicos, há poucas coisas mais concretas e práticas do que a Química.

\section{A químICA ANALÍtICA E DO MEDO NAS AVENTURAS DE JOÃO Sem Medo}

Em as “Aventuras de João sem Medo” [15], de 1963, do escritor José Gomes Ferreira, há vários episódios relacionados com o medo e a Química que são relevantes. Neste livro, reformulado a partir de um folhetim no jornal para jovens, “O Senhor Doutor”, escrito em 1933, as aventuras mágicas, mas quase sempre irónicas e com aspectos subtis de crítica social e política, sucedem-se de forma vertiginosa. Claro, que tratando-se de fantasia e magia toda a imaginação é permitida, mas é, mesmo assim interessante olhar para os episódios nos quais o herói se transforma em fonte ou em que corre o risco de ser envenenado pelo ar onde se volatilizou a personagem secundária João Medroso. Ora, tendo o corpo humano cerca de 65\% de água, não é muito chocante que se faça a transformação numa fonte, mas o herói adverte: Não te esqueças de mandar analisar a água. Oxalá não tenha muito amónio, muito lítio, muito estrôncio, muita sílica... Desconhece-se a razão da escolha destas substâncias em particular, mas é com certeza um aspecto químico que pode ser considerado na análise do livro. Já a volatilização do João Medroso, provocando o envenenamento do ar, apresenta mais problemas e outros tantos caminhos para enriquecer a fantasia com química: (...) estás a respirar o João Medroso (...) Transformei-o em ar. Mudei-lhe os cabelos em oxigénio, os olhos em azoto, as mãos em vapor de água, os dentes em anidrido carbónico... Resultado o João Medroso está a entrar lentamente em $t$. Trata-se de uma óptima oportunidade para relembrar aos estudantes as composições elementares do corpo humano (Figura 5) e isso não retira beleza ao texto.

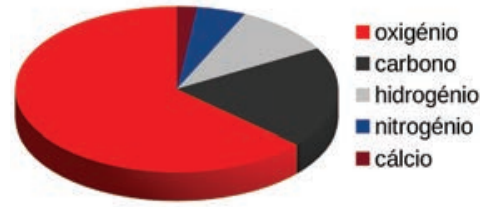

A

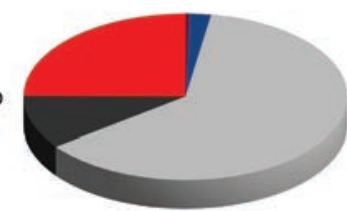

B
Figura 5 - Composição elementar típica do corpo humano em massa (A) e fracção do número de átomos (B)

Os elementos envolvidos (hidrogénio, oxigénio, carbono e nitrogénio) estão mais ou menos correctos. A volatilização da infeliz personagem teria com certeza mais vapor de água do que nitrogénio e originaria dióxido de carbono, mas dificilmente originaria oxigénio, o qual ficaria incorporado no dióxido de carbono e água, mas a fantasia é (quase) possível em termos químicos.

Já o que poderia causar o medo não seriam as moléculas referidas, mas sim moléculas mais complexas, por exemplo neurotransmissores, que subsistiriam na volatilização.

\section{MEMÓRIAS QUímICAS DO PASSADO}

Num dos livros da série "Viagens no Tempo" de Ana Maria Magalhães e Isabel Alçada, "Viagem à Índia” [16], os jovens heróis curam um marinheiro com escorbuto dando-lhe tangerinas. Isso é uma acção que hoje parece óbvia, mas que demorou séculos e muito sofrimento a descobrir. A descrição do escorbuto em “Os Lusíadas” (Canto 5: 81), de Luís de Camões, é terrível:

\section{E foi, que de doença crua e feia}

A mais que eu nunca vi, desempararam

Muitos a vida e em terra estranha e alheia

Os ossos para sempre sepultaram.

Quem haverá que sem ver o creia?

Que tão disformemente ali lhe incharam

As gengivas na boca, que crescia

A carne, e juntamente apodrecia.

Esta doença levava à morte de mais de um terço dos tripulantes dos barcos e irão passar quase dois séculos, desde a descrição de Camões, até que se confirme e aceite, sem margem para dúvidas, que os alimentos frescos preveniam e curavam o escorbuto. E só no século XX se descobriu que essa terrível doença era afinal causada pela deficiência de ácido ascórbico, também conhecido por vitamina $\mathrm{C}$ (Figura 6, 11). Devido às implicações que esta molécula teve para a história da humanidade, Penny Le Couteur e Jay Burreson [17] consideram-na, com justiça, uma das 17 moléculas, ou tipos de moléculas, que mudaram o mundo.

“O Cavaleiro da Dinamarca” [18], datado de 1964, de Sophia de Mello Breyner Andresen, é um livro que nos transporta numa viagem pela Europa até à Terra Santa. Nas suas interacções com a Química, é muito relevante a parte em que o cavaleiro fica doente e o seu tratamento [18]:

Mas já no fim do caminho, a pouca distância de Génova, adoeceu. Foi talvez do sol que o escaldava enquanto cavalgava por vales e montes, ou foi da água que bebeu de um poço onde iam à noite beber os sardões. Tremendo de febre, foi bater à porta dum convento. Os frades que o recolheram tiveram grande trabalho para o salvar, pois o Cavaleiro parecia ter o sangue envenenado e delirava dia e noite. (...)

Os frades trataram-no com chás de raizes de flores, com pílulas de aloés, com xaropes de mel e vinho quente, com pós misteriosos e emplastros de farinhas e ervas. (...)

Só no século XX começaram a conhecer-se os mecanismos moleculares e químicos das doenças. Mas há algumas dúvidas para as quais ainda não temos respostas simples. Por que razão adoecem mais facilmente as pessoas que apanham sol ou frio? Ou, será que essa afirmação é cientificamente válida e pode ser verificada? No tempo em que viveu o cavaleiro, a vida dos animais e a contaminação das águas eram mistérios explicados com preconceitos e conceitos mágicos. Na verdade, em geral, os sardões não são 


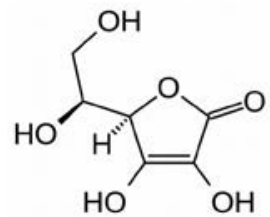

11

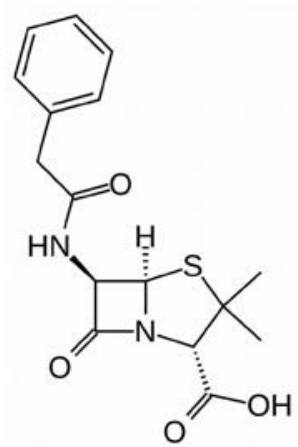

12

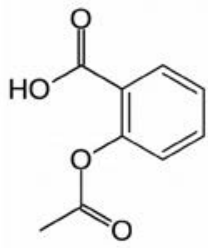

13

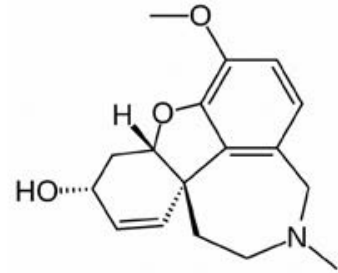

14

Figura 6 - "Moléculas-maravilha” com notável presença na Literatura: ácido ascórbico (11); penicilina G (12); ácido acetilsalicílico (13); galantamina (14)

venenosos e alimentam-se tanto de noite como de dia [19]. E, embora existam alguns lagartos que são mais ou menos venenosos (os dragões de Komodo) estes não contaminam as águas. As águas das fontes do tempo de cavaleiro estariam, de facto, provavelmente, contaminadas, mas a razão era outra.

Nesse tempo as contaminações eram, em geral, devidas a falta de higiene. As grandes epidemias de cólera estavam relacionadas com os esgotos e despejos que contaminavam as fontes e cursos de água, mas, na ausência das informações que a Ciência moderna veio trazer, era comum pensar-se que seriam causadas por bichos peçonhentos, maldade humana, ou castigo divino. Hoje em dia podemos evitar e resolver a contaminação das águas e alimentos, controlar a sua qualidade e tratar as infecções, em grande parte devido à Química.

São também relevantes os remédios dos frades que Sophia de Melo Breyner refere. Trata-se de medicamentos à base de plantas e, na altura, não havia outros que fossem tão eficazes e seguros. Era com certeza melhor para a saúde um chá ou um emplastro de plantas do que uma sangria. E muitos destes tratamentos naturais eram, de facto, eficazes. A casca do salgueiro para as febres, ou o hipericão e os aloés para aumentarem as defesas do organismo. Mas é preciso notar que os tratamentos com produtos naturais têm quase sempre riscos pois muitas plantas são venenosas ou têm efeitos secundários. Também os primeiros medicamentos sintéticos à base de mercúrio, antimónio, ouro, prata, e outros metais, desenvolvidos pelos alquimistas apresentavam bastantes riscos. Com o aparecimento de antibióticos, como a penicilina (Figura 6, 12), antipiréticos como a aspirina (Figura 6, 13), e muitos outros medicamentos, a infecção vulgar de que sofreu, provavelmente, o cavaleiro não seria tão dramática. Os medicamentos desenvolvidos no século XX em conjunto com a higiene e controlo da qualidade das águas e alimentos contribuíram para que a esperança de vida média quase duplicasse no último século.

Na “Odisseia” de Homero existe uma referência a uma planta mágica que evitou que Ulisses fosse encantado pela feiticeira Circe. Essa planta tem sido associada àquela na qual se descobriu a galantamina (Figura 6, 14), usada actual- mente para minimizar os efeitos da doença de Alzheimer e da perda de memória associada. Nas versões juvenis da “Odisseia” de João de Barros [20] e Maria Alberta Menéres [21], a referência a esta planta, assim como o papel da perda de memória para a eficácia do encantamento de Circe, está também descrita, embora com menos pormenores. Um aspecto muito importante sobre o papel da Química é o facto da galantamina e outras moléculas, inicialmente retiradas de plantas e animais, serem hoje em dia obtidas de forma sintética, o que permite preservar espécies raras e obter medicamentos de forma mais económica, segura e em quantidade suficiente.

A perda e recuperação da memória é também muito importante numa das aventuras dos meninos mais malcriados do mundo, "Iratan e Iracema” [22], heróis de um livro de 1939, que foi inicialmente um folhetim radiofónico para jovens, de Olavo d'Eça Leal. Este livro tem a particularidade de envolver uma descrição bastante elaborada da Alquimia e alguns dos seus aspectos filosóficos e ainda uma visita ao Inferno de Dante, realçando o principal castigo: o tédio. À saída, tendo perdido a memória, encontram um Vendedor de Memórias, o que pode ser um pretexto para relembrar o papel que a Química tem na formação das memórias e dos sonhos e fantasias.

\section{NATUREZA, SUSTENTABILIDADE E FUTURO}

Monteiro Lobato é um escritor brasileiro que nasceu em 1882 e morreu em 1948 e que hoje, aparentemente, pouco se lê na versão original em Portugal, embora quase todas as pessoas conheçam pelo menos uma versão da série televisiva "Sítio do Pica-pau Amarelo" inspirada nos seus livros para jovens. Lobato foi também um autor que muito pugnou pela modernização do Brasil, em especial da exploração do seu petróleo e recursos mineiros por companhias locais, tendo tido uma notável intervenção social e política.

Emília, é uma boneca de trapos que quer reformar a natureza e, para isso, precisa de um biólogo molecular, que possa manipular o material genético de animais e plantas (embora vá ter de esperar quase uma década até ao ADN ser descoberto), e precisa também de um químico. Um químico que invente, por exemplo, um livro que possa ser comido. 
Em “A Reforma da Natureza” [23], datado de 1941, Emília imagina que os químicos poderão inventar livros que começam pela sopa e terminam na sobremesa: lê-se o livro e almoça-se! Há uma ideia semelhante em "Charlie e a Fábrica de Chocolate”, livro de 1964 do escritor inglês Roald Dahl, do qual existem duas versões para cinema. Neste livro, uma menina imprudente e impertinente experimenta uma pastilha elástica que (tal como no livro comestível de Emília) poderia fornecer uma refeição completa à medida que era mastigada. No entanto, se em "A Reforma da Natureza” o livro comestível não passa de uma ideia, em "Charlie e a Fábrica de Chocolate”, a pastilha elástica ainda não está suficientemente desenvolvida e testada e, por isso, os resultados são desastrosos. É de notar que os problemas decorrentes de uma investigação científica mal conduzida e da falta de registos adequados encontram-se em muitas obras como, por exemplo, em "Dr. Jeckyl e Mr. Hyde" de Robert Louis Stevenson e em "A Estranha Morte do Professor Antena” de Mário de Sá Carneiro, entre outros [5].

Mas voltemos às invenções da Emília. Hoje são comuns os bolos de aniversário com fotografias que se podem comer, mas ninguém, parece estar interessado em livros comestíveis. Muitas vezes as ideias são disparatadas e são abandonadas, outras revelam-se descobertas úteis. Em qualquer dos casos, para que funcionem é preciso quase sempre conhecer, controlar e dominar os processos químicos que concretizam essas ideias.

O caminho que se fez até se obterem pigmentos com cores variadas que podem ser comidos com segurança é muito maior e mágico do que pode parecer [18]. Hoje, que vivemos num mundo muito mais seguro e cheio de cores vivas com sabores e cheiros agradáveis proporcionados pela Química, quase não conseguimos imaginar como seria no passado.

A maior parte dos pigmentos que podiam ser comidos com relativa segurança, até há relativamente pouco tempo, embora naturais, eram facilmente degradáveis e tinham cores muito sensíveis ao $\mathrm{pH}$. Por outro lado, uma boa parte dos pigmentos inorgânicos conhecidos eram em geral muito tóxicos: o vermilhão, o mínio, o amarelo de cádmio, entre outros.

A revolução que a Química moderna veio trazer, através dos processos de síntese, identificação e extracção de compostos é única e fascinou as pessoas durante todo o século XIX até à década de sessenta do século XX, altura em que começou a surgir o que alguns autores designam como "quimiofobia”, em parte como reacção a um mundo demasiado optimista e com uma fé inabalável nos produtos artificiais e sintéticos que a Química revelou ao mundo. E da "quimiofobia" passou-se lentamente para a quase invisibilidade actual. E, no entanto, a Química continua todos os dias a aumentar as suas capacidades de produção e detecção de novas moléculas, actualmente tendo também uma enorme preocupação com a sustentabilidade através, por exemplo, da Química Verde. Se o fascínio pela Química não for urgentemente reencontrado, as vocações e sonhos dos jovens em relação à Química continuarão a diminuir e, com isso, a qualidade de vida e segurança que a Química veio trazer ao nosso mundo estará em rico de estagnar ou degradar-se de forma irremediável.

Perceber os mecanismos químicos pelos quais as coisas acontecem não lhes retira poesia, antes as dignifica e eleva, dando-lhes mais dimensões do que aquelas que se julgava à partida. Evidenciar que a Química está também presente na Literatura, pode ser um caminho para uma convivência mais saudável com esta Ciência, diminuir a "quimiofobia” e aumentar o entusiasmo dos jovens pela Química, mostrando que esta Ciência, assim como a investigação em Química, são além de fascinantes, fundamentais para a nossa vida e para o futuro da Humanidade.

\section{Agradecimentos}

O Centro de Química de Coimbra é apoiado pela Fundação para a Ciência e a Tecnologia (FCT), através do projecto Pest-OE/QUI/UI0313/2014.

\section{REFERÊNCIAS}

[1] J.P. André, Química (Boletim da SPQ) 127 (2012) 57-63

[2] Michael Faraday “A História Química de um Vela”, tradução e notas de Maria Isabel Prata e Sérgio Rodrigues, prefácio de Sebastião Formosinho, Imprensa da Universidade de Coimbra e SPQ, Coimbra, 2011

[3] W.B. Jensen, Chem. Intell. 3 (1007) 23-32

[4] C. Bravo-Villasante, "História da Literatura Infantil Universal”, Editorial Vega, Lisboa, 1977

[5] S.P.J. Rodrigues, manuscrito em preparação para publicação, 2014; algumas versões iniciais de parte dos textos do manuscrito podem ser encontradas no blogue "de Rerum Natura”, incluindo alguns aspectos da Química na literatura infantil que não foram referidos no presente texto, http:// dererummundi.blogspot.pt/search/label/Química (acedido em 2 de Abril de 2014)

[6] R. Highfield, “A Ciência e a Magia em Harry Potter”, Editorial Magnólia, Vila Nova de Famalicão, 2007

[7] Aquilino Ribeiro, “O Romance da Raposa”, Bertrand, Lisboa, 1996

[8] S. Gomes, L.G. Dias, L.L. Moreira, P. Rodrigues, L. Estevinho, Food. Chem. Tox. 48 (2010) 544-548; S. Bogdanov, P. Martin, "Honey Authenticity: a Review” http://www.beehexagon.net/-files/file/fileE/Honey/AuthenticityRevue_Internet.pdf (acedido em 2 de Abril de 2014)

[9] C. Arrabal, M. Cortijoa, B.F. Simón, M.C.G. Vallejo, E. Cadahía, Biochem. System. Ecol. 33 (2005) 1007-1016; S. Rezzi, A. Bighelli, V. Castola, J. Casanova, Ind. Crops Prod. 21 (2005) 71-79

[10] K.M. Service, R.G. Brereton, S. Harris, Analyst 126 (2001) 615-623

[11] W.F. Wood, B.G. Sollers, G.A. Dragoo, J.W. Dragoo, J. Chem. Ecology 8 (2002) 1865-1870

[12] M. Fendt, T. Endres, Neurosci. Biobehaviour Rev. 32 (2008) 1259-1266 
[13] Jean Webster, “O Papá das Pernas Altas”, Civilização, Porto, 1961

[14] C. Cobb, M.L. Fetterolf "The Joy of Chemistry: The Amazing Science of Familiar Things”, Prometheus Books, New York, 2005

[15] José Gomes Ferreira, “Aventuras de João sem Medo”, 25. ${ }^{\text {a }}$ ed, Publicações D. Quixote, Lisboa, 2005

[16] Ana Maria Magalhães e Isabel Alçada, "Viagem à Índia”, 2. ${ }^{\text {a }}$ ed, Caminho, Lisboa, 2009

[17] Sophia de Mello Breyner Andresen "O cavaleiro da Dinamarca”, 56. ${ }^{a}$ ed, Figueirinhas, Lisboa, 2001

[18] P. Le Couteur, J. Burreson, “Napoleon’s Buttons: How 17
Molecules Changed History”, Tarcher-Penguin Putnam, New York, 2003

[19] J.A. Hodar, F. Campos, B.A. Rosales, J. Arid Environm. 33 (1996) 95-107

[20] João de Barros, “A Odisseia: adaptação em prosa do poema de Homero”, 33. a ed, Civilização, Lisboa, 2004

[21] Maria Alberta Menéres, “Ulisses”, 39. a ed, Asa II, Alfragide, 2013

[22] Olavo D’Eça Leal, "Iratan e Iracema”, 5. a ed, Editorial Vega, Lisboa, 2002

[23] Monteiro Lobato, "A reforma da Natureza”, Companhia Editora Nacional, São Paulo, 1941

\section{ActualidAdes CIENTiFicAs}

\section{VIA ABERTA PARA O $\mathrm{P}_{2} \mathrm{O}_{4}$}

Investigadores da Universidade da Geórgia, EUA, foram os primeiros a obter com sucesso uma forma estável da molécula de $\mathrm{P}_{2} \mathrm{O}_{4}$, a muito procurada análoga de fósforo do $\mathrm{N}_{2} \mathrm{O}_{4}$.

Embora o fósforo seja o elemento imediatamente abaixo do nitrogénio na Tabela Periódica, o comportamento químico destes dois elementos é relativamente diferente em vários aspectos. Por exemplo, o $\mathrm{N}_{2}$ é bastante estável e o principal constituinte da atmosfera terrestre. Em contraste, $\mathrm{P}_{2}$ é transiente e apenas observado a temperaturas elevadas. $\mathrm{O}$ nitrogénio forma uma série de óxidos isoláveis, como $\mathrm{NO}, \mathrm{NO}_{2}$ e $\mathrm{N}_{2} \mathrm{O}_{\mathrm{x}}(\mathrm{x}=1,3,4,5)$. O fósforo forma óxidos estáveis, como $\mathrm{P}_{4} \mathrm{O}_{6}$ ou $\mathrm{P}_{4} \mathrm{O}_{10}$, mas os análogos de nitrogénio, como $\mathrm{PO}, \mathrm{PO}_{2}$ e $\mathrm{P}_{2} \mathrm{O}_{\mathrm{x}}(\mathrm{x}=1,3,4,5)$, são altamente reactivos e, tipicamente, apenas estudados em fase gasosa ou em experiências a temperaturas criogénicas. Consequentemente, as aplicações sintéticas destes óxidos de fósforo reactivo estão severamente limitadas.

A equipa liderada por Gregory Robinson conseguiu obter uma molécula estável contendo $\mathrm{P}_{2} \mathrm{O}_{4}$ por uma via engenhosa através da estabilização prévia de $\mathrm{P}_{2}$ usando um carbeno $N$-heterocíclico e posterior oxidação com oxigénio molecular, em condições suaves.
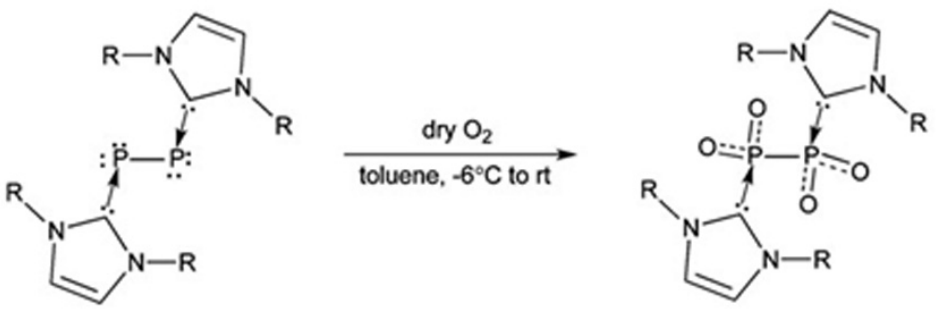

Na caracterização do composto, os resultados acabaram por ser uma surpresa. Enquanto cálculos teóricos prevêem que a estrutura energeticamente mais favorável é uma estrutura com oxigénio em ponte, $\mathrm{O}_{2} \mathrm{POPO}$, a equipa descobriu que a estrutura obtida corresponde ao isómero menos favorável, $\mathrm{O}_{2} \mathrm{P}_{-} \mathrm{PO}_{2}$. Descobriram ainda que a molécula de $\mathrm{P}_{2} \mathrm{O}_{4}$ estabilizada pelos carbenos $N$-heterocíclicos constitui o primeiro exemplo de um óxido de fósforo com um comportamento de ácido de Lewis.

“O facto de se poder induzir propriedades de ácido de Lewis à molécula $\mathrm{P}_{2} \mathrm{O}_{4}$, confirma ainda que as bases de Lewis, tais como os carbenos $N$-heterocíclicos, são ferramentas versáteis que podem ajudar químicos a aceder à química inexplorada de óxidos de fósforo e eventualmente de óxidos de outros elementos”, referiu Gregory Robinson.

Enquanto a questão das potenciais aplicações que podem advir do trabalho realizado permanecem ainda sem resposta, Robinson e a sua equipa continuam a estudar a reactividade da molécula. “A estabilização da molécula de $\mathrm{P}_{2} \mathrm{O}_{4}$ apresenta possibilidades sintéticas e catalíticas interessantes”, concluiu.

(adaptado de "First route to diphosphorus tetroxide”, http://www.rsc.org/chemistryworld/2014/01/first-route-diphosphorus-tetroxide e de Y. Wang, Y. Xie, P. Wei, H.F. Schaefer, P. von R. Schleyer, G.H. Robinson, J. Am. Chem. Soc. 135 (2013) 19139, DOI: 10.1021/ja411667f)

Paulo Mendes pjgm@uevora.pt 


\section{Essential reading for multidisciplinary chemists}

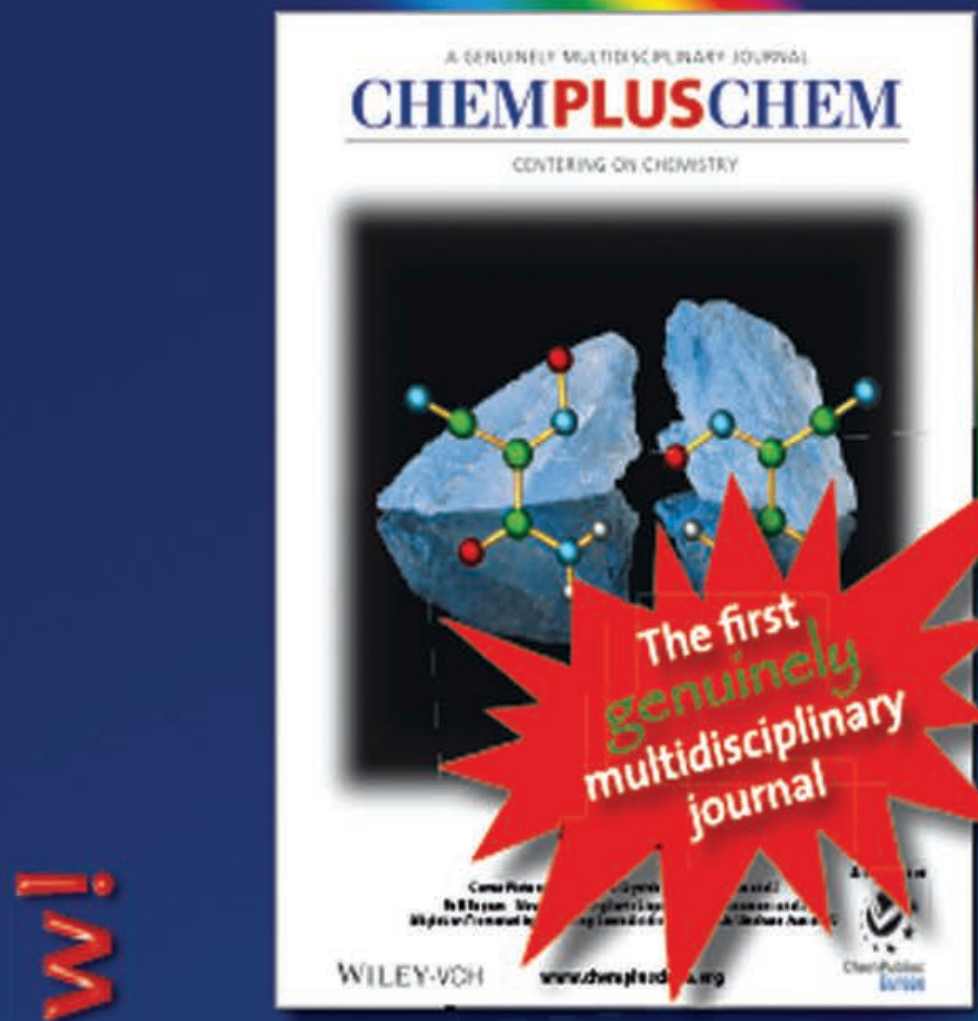

\section{www.chempluschem.org}

Editorial Team

Editor:Neville Compton

Deputy Editor:Marisa Spiniel lo

ChemPluschem presents multidisciplinary

research in a variety of formats:

Minireviews

Reviews

Full Papers

Communications

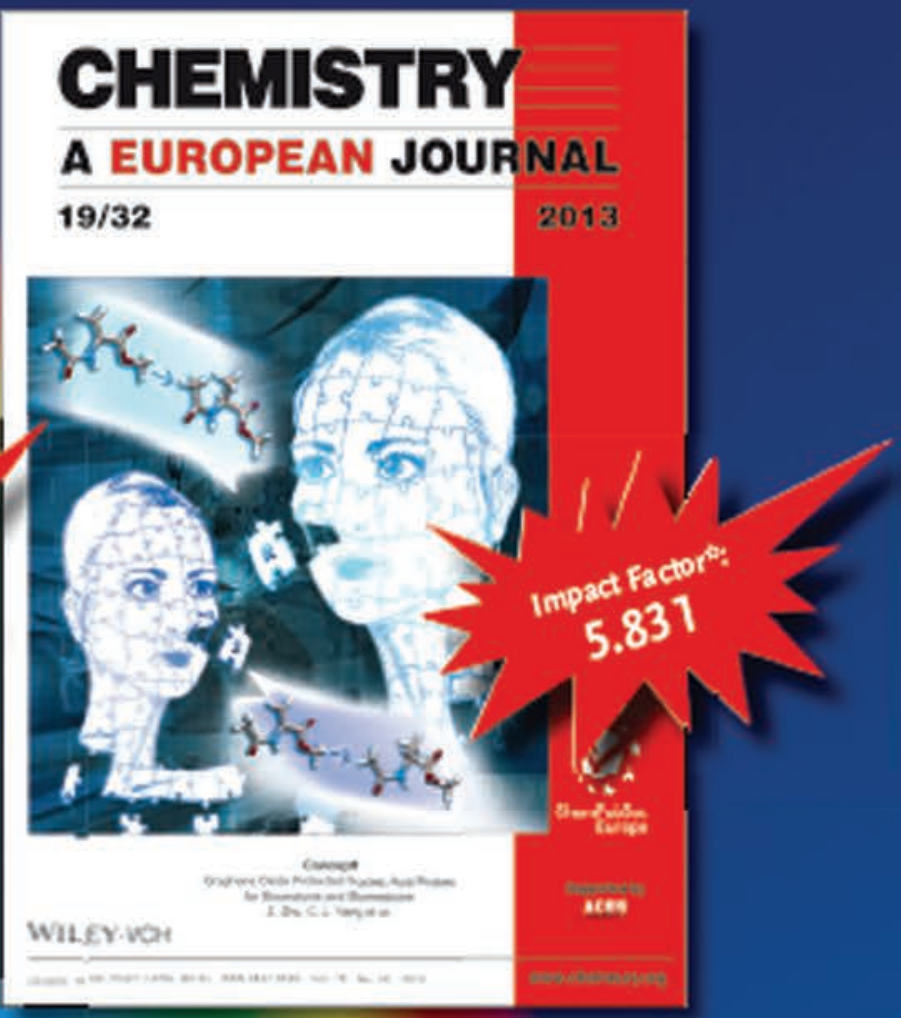

www.chemeurj.org

Editorial Team

Editor: Neville Compton

Deputy Editors: Anne Deveson and Elisa beth Roedern

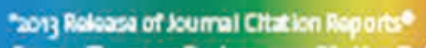

Source Thomesn Rraters, 2012 Cratbin Data

ChemPluschem succeeds the

Collection of Gechoslovak Chemicd

Communications

Articles in ChemPluschem cover at least two different field of chemistry or one of chemistry and one of another scientific discipline:

general diemistry

biotechnology

organic chemistry

inorganic chemistry

physical chemistry

macromolecularchemistry analytical chemistry

biological chemistry

organomatallic chemistry

polymer chemistry

computational chemistry

erwironmental chemistry

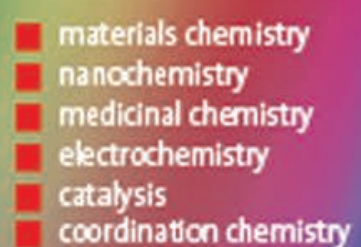

manuscript) press

A joumalof:

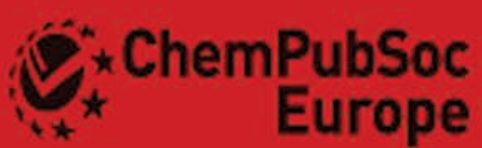

an organiastion

comprising

16 European

chemical societis
Published by:

WILEY-VCH

\section{व
कै
कू
के}

